\title{
RB localizes to DNA double-strand breaks and promotes DNA end resection and homologous recombination through the recruitment of BRG1
}

\author{
Renier Vélez-Cruz, ${ }^{1}$ Swarnalatha Manickavinayaham, ${ }^{1}$ Anup K. Biswas, ${ }^{1,3}$ Regina Weaks Clary, ${ }^{1,2}$ \\ Tolkappiyan Premkumar, ${ }^{1,2}$ Francesca Cole, ${ }^{1,2}$ and David G. Johnson ${ }^{1,2}$ \\ ${ }^{1}$ Department of Epigenetics and Molecular Carcinogenesis, The University of Texas MD Anderson Cancer Center, Smithville \\ Texas 78957, USA; ${ }^{2}$ The University of Texas Graduate School of Biomedical Sciences at Houston, Houston, Texas 77225, USA
}

The retinoblastoma $(\mathrm{RB})$ tumor suppressor is recognized as a master regulator that controls entry into the $S$ phase of the cell cycle. Its loss leads to uncontrolled cell proliferation and is a hallmark of cancer. RB works by binding to members of the E2F family of transcription factors and recruiting chromatin modifiers to the promoters of E2F target genes. Here we show that RB also localizes to DNA double-strand breaks (DSBs) dependent on E2F1 and ATM kinase activity and promotes DSB repair through homologous recombination (HR), and its loss results in genome instability. RB is necessary for the recruitment of the BRG1 ATPase to DSBs, which stimulates DNA end resection and HR. A knock-in mutation of the ATM phosphorylation site on E2F1 (S29A) prevents the interaction between E2F1 and TopBP1 and recruitment of RB, E2F1, and BRG1 to DSBs. This knock-in mutation also impairs DNA repair, increases genomic instability, and renders mice hypersensitive to IR. Importantly, depletion of RB in osteosarcoma and breast cancer cell lines results in sensitivity to DNA-damaging drugs, which is further exacerbated by poly-ADP ribose polymerase (PARP) inhibitors. We uncovered a novel, nontranscriptional function for RB in HR, which could contribute to genome instability associated with RB loss.

[Keywords: homologous recombination; DNA end resection; retinoblastoma; E2F1; BRG1; SWI/SNF]

Supplemental material is available for this article.

Received July 29, 2016; revised version accepted November 3, 2016.

The retinoblastoma $(\mathrm{RB})$ tumor suppressor is one of the most prominent transcriptional regulators of cell cycle entry (Dick and Rubin 2013). RB represses the expression of genes important for cell cycle progression by binding to members of the E2F family of transcription factors and recruiting chromatin-modifying proteins, such as histone deacetylases and SWI/SNF ATPases, to the promoters of E2F target genes (Degregori and Johnson 2006). Hyperphosphorylation of RB by cyclin-dependent kinases during progression from G1 to $S$ phase causes the dissociation of RB from E2F, thereby allowing E2F to stimulate transcription of genes important for cell proliferation by recruiting coactivators, such as histone acetyltransferases (HATs) (Degregori 2011; Dick and Rubin 2013). Other stimuli, such as differentiation and DNA damage, can also trigger the formation of transcriptionally active

\footnotetext{
${ }^{3}$ Present address: Herbert Irving Comprehensive Cancer Center, Columbia University, New York, NY 10032, USA. Corresponding author: djohnson@mdanderson.org Article is online at http://www.genesdev.org/cgi/doi/10.1101/gad.288282. 116.
}

E2F-RB complexes (Ianari et al. 2009; Dick and Rubin 2013; Flowers et al. 2013).

Germline mutations in the $R B 1$ gene cause retinoblastoma, a rare pediatric cancer, as well as osteosarcomas and other cancers. The RB protein is also deregulated in many other human cancers through mutations in upstream regulators of RB phosphorylation (Dick and Rubin 2013). The main driver of cellular transformation in the absence of RB is thought to be unchecked cell proliferation. RB loss may also promote tumor development through inhibition of differentiation or impaired apoptosis (Ianari et al. 2009; Dick and Rubin 2013; Flowers et al. 2013; Hilgendorf et al. 2013). In addition, RB has transcription-independent functions on chromosome condensation and maintenance of telomeric heterochromatin (Gonzalo et al. 2005; Coschi et al. 2010; Manning et al. 2010). Since RB interacts with a large variety of

(C) 2016 Vélez-Cruz et al. This article is distributed exclusively by Cold Spring Harbor Laboratory Press for the first six months after the full-issue publication date (see http://genesdev.cshlp.org/site/misc/terms.xhtml). After six months, it is available under a Creative Commons License (Attribution-NonCommercial 4.0 International), as described at http://creativecommons.org/licenses/by-nc/4.0/. 
proteins and has been shown to play multiple roles in addition to its canonical role in transcription, this tumor suppressor has been described as a "multifunctional chromatin-associated protein" (Dyson 2016).

Like RB, E2F1 is known to have functions that are independent of its ability to regulate transcription (Velez-Cruz and Johnson 2012; Biswas et al. 2014; Malewicz and Perlmann 2014). Upon DNA damage, E2F1 is phosphorylated at Ser31 by the ATM and ATR kinases, which generates a binding motif for the sixth BRCA1 C-terminal (BRCT) domain of the TopBP1 protein (Liu et al. 2003). TopBP1 recruits E2F1 to sites of DNA damage through this phosphospecific interaction independently of the DNA-binding or transcriptional activation domains of E2F1 (Liu et al. 2003; Guo et al. 2010). E2F1-deficient cells display genome instability and are impaired for the repair of both UV-induced DNA damage and DNA double-strand breaks (DSBs) (Guo et al. 2010, 2011; Chen et al. 2011). Defects in DNA repair in the absence of E2F1 correlate with impaired recruitment of DNA repair proteins to sites of damage.

Defects in the repair of DSBs drive genome instability, which is a hallmark of cancer that correlates with worse outcomes (Hanahan and Weinberg 2011; Burrell et al. 2013). DSBs are highly cytotoxic lesions that are generated during normal cellular metabolism and by exogenous insults such as chemotherapeutic agents and radiation (Aparicio et al. 2014). DSBs can be repaired by nonhomologous end-joining (NHEJ) or homologous recombination (HR). NHEJ mainly entails the ligation of DNA ends and is highly mutagenic, while HR requires a sister chromatid template and is less mutagenic than NHEJ (Jasin and Rothstein 2013).

During HR, the MRN complex (comprised of the MRE11, NBS1, and RAD50 proteins), together with the ATM kinase, initiates DNA damage signaling (Paull and Lee 2005). The MRN complex, along with CtIP, also initiates DNA end resection at DSBs (Sartori et al. 2007; Mimitou and Symington 2009). During this process, long stretches of ssDNA with free 3 ' ends are generated, which requires the action of MRE11 and CtIP nucleases, and these regions are rapidly coated by RPA (Sartori et al. 2007; Mimitou and Symington 2009). In turn, the BRCA2 protein helps to load the RAD51 recombinase that forms filaments along these ssDNA regions, thus replacing RPA (Liu and West 2002; Jasin and Rothstein 2013; Aparicio et al. 2014). Deficiencies in this process, such as mutations in the BRCA2 gene, result in increased genome instability due to the impairment of the HR pathway and increased utilization of the more mutagenic NHEJ (Yu et al. 2000; Liu and West 2002; Jasin and Rothstein 2013).

Recent work has shown the importance of chromatin structure in the repair of DSBs and particularly how chromatin modifiers and remodelers affect DNA end resection (Sartori et al. 2007; Mimitou and Symington 2009; Price and D'andrea 2013; Gursoy-Yuzugullu et al. 2016). It is clear that nucleosomes pose a barrier to the processing of DNA ends, and this barrier must be relieved in order for end resection to occur (Mimitou and Symington 2011). Chromatin remodeling enzymes have been shown to modulate nucleosome dynamics at DSBs and regulate DNA end resection. For instance, the INO80 ATPase was shown to stimulate DNA end resection /Gospodinov et al. 2011), and, more recently, it was suggested that this effect in resection was mediated by the removal of the histone variant $\mathrm{H} 2 \mathrm{AZ}$ from the break site (Alatwi and Downs 2015; Gursoy-Yuzugullu et al. 2015). Moreover, the HEL1 helicase was shown to promote end resection and HR likely by modifying nucleosomes at the site of the break (Costelloe et al. 2012). The BRG1 ATPase has also been shown to be recruited to DSBs to stimulate repair (Gong et al. 2015; Qi et al. 2015) and also repress transcription in order for efficient repair to take place (Kakarougkas et al. 2014). While these and other chromatin remodelers are known to be critical for altering chromatin structure to promote DSB repair, the mechanisms by which these proteins are recruited to sites of DSBs are poorly understood.

In the present study, we demonstrate that $\mathrm{RB}$ is recruited to DSBs dependent on E2F1 and ATM kinase activity. Furthermore, RB is required for the recruitment of BRG1 to DSBs. RB-deficient cells are defective in the clearance of phosphorylated histone $\mathrm{H} 2 \mathrm{AX}(\gamma \mathrm{H} 2 \mathrm{AX})$, DNA end resection, and $\mathrm{HR}$ and also display increased chromosomal abnormalities upon exposure to IR. The localization of RB to DSBs requires E2F1 Ser31 (Ser29 in mice), a site phosphorylated by the ATM/ATR kinases after DNA damage. Mouse embryonic fibroblasts (MEFs) from a mouse model with an E2F1 S29A mutation display the same DNA repair defect as RB-deficient cells, and E2 $f 1^{\text {S29A/S29A }}$ mice are hypersensitive to IR, thus illustrating the importance of this repair function of RB. Moreover, depletion of RB in osteosarcoma and breast cancer cells rendered these cells sensitive to DSB-inducing agents as well as poly-ADP ribose polymerase (PARP) inhibitors, a feature of HR-defective cells. This novel function of RB in HR could explain the genome instability and DNA damage sensitivity observed in RB-deficient human cancers. Finally, these findings further strengthen an emerging paradigm in which transcription factors and coregulators play important roles in the control of other processes beyond transcription that could also contribute to carcinogenesis.

\section{Results}

$R B$ localizes to DSBs dependent on E2F1 and ATM kinase activity

Previous studies found that E2F1 forms IR-induced nuclear foci that colocalize with known markers of DSBs, such as $\gamma \mathrm{H} 2 \mathrm{AX}$ (Liu et al. 2003; Chen et al. 2011). Given that E2F1 and RB form a complex in response to DNA damage (Supplemental Fig. S1a; Dick and Dyson 2003; Inoue et al. 2007; Ianari et al. 2009), we performed an in situ extraction protocol to assess through confocal microscopy whether RB also formed foci in response to IR. RB formed nuclear foci $30 \mathrm{~min}$ after IR; these foci colocalized with $\gamma \mathrm{H} 2 \mathrm{AX}$ foci (Fig. 1A; Supplemental Fig. S1b,c), and both foci disappeared with similar kinetics. RB foci were observed in the majority of asynchronously growing cells $(\sim 90 \%)$ (Supplemental Fig. S1c). RB foci were not observed 

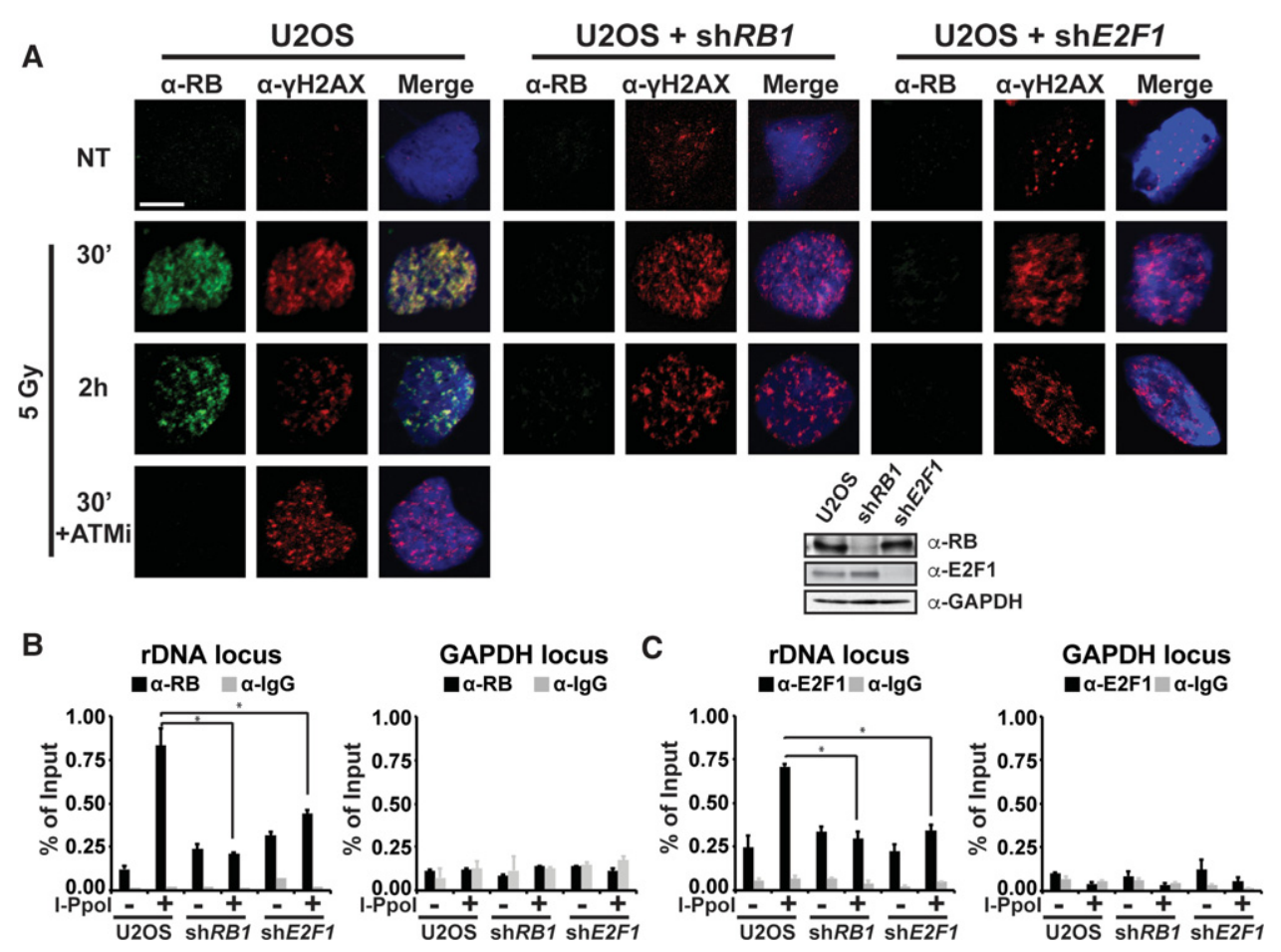

Figure 1. RB localizes to DSBs dependent on E2F1 and ATM kinase activity. (A) Parental U2OS cells or U2OS cells expressing shRNA targeting either RB (U2OS + shRB1) or E2F1 (U2OS + shE2F1) were mock-treated (NT) or treated with 5 Gy of IR and subjected to in situ extraction. Parental cells were also pretreated with $1 \mu \mathrm{M}$ ATM inhibitor (ATMi) KU-60019 for $1 \mathrm{~h}$ prior to IR. Cells were immunofluorescently stained with the indicated antibodies and counterstained with DAPI. Representative confocal microscopy images show IR-induced foci of RB (green) and $\gamma \mathrm{H} 2 \mathrm{AX}$ (red) and colocalization of these foci (yellow; merge). Bar, $10 \mu \mathrm{m}$. The Western blot control shows depletion of RB or E2F1 in the respective cell lines, with GAPDH as a loading control. $(B, C)$ U2OS cells were uninfected $(-)$ or infected $(+)$ with retrovirus expressing the homing endonuclease I-PpoI fused to a modified estrogen receptor (HA-ER*-I-PpoI) and treated with $2 \mu M$ tamoxifen for $12 \mathrm{~h}$. Chromatin immunoprecipitation (ChIP) was performed using antibodies against RB or E2F1. Quantitative PCR (qPCR) was performed for the rDNA locus (489 base pairs [bp] 3' to the I-PpoI cut site) and the GAPDH promoter as a negative control (no I-PpoI cut site). The percentage (\%) of input refers to the amount of DNA obtained from the immunoprecipitation of the given factor divided by the total amount of DNA (input). All experiments were done in triplicate. Graphs represent averages \pm SD. $\left({ }^{*}\right) P<0.05$.

in U2OS cells expressing shRNA against RB1 or E2F1, indicating that $\mathrm{RB}$ focus formation is dependent on E2F1 (Fig. 1A). Moreover, pretreatment of U2OS cells with the ATM inhibitor KU-60019 abolished RB focus formation in response to IR (Fig. 1A, bottom panel, $30 \mathrm{~min}$ +ATMi), similar to what has been shown for E2F1 foci (Liu et al. 2003).

To confirm our microscopy findings, we used the homing endonuclease I-PpoI system (Berkovich et al. 2007) to monitor RB recruitment to DSBs by chromatin immunoprecipitation (ChIP). In U2OS cells, RB was recruited to the flanking region of the I-PpoI cut site in the ribosomal DNA $(r D N A)$ gene following I-PpoI induction (Fig. 1B) as well as to an I-PpoI cut site on chromosome 1 (Supplemental Fig. S1d) but not to the GAPDH locus, where there is no I-PpoI site (Supplemental Fig. S1e). There was no enrichment of RB at the I-PpoI cut site in cells knocked down for RB or E2F1, thus confirming that recruitment of RB to DSBs is dependent on E2F1. Interestingly, we also observed that the recruitment of E2F1 to DSBs was reduced in the absence of RB, suggesting that the recruitment of these two proteins to break sites may be mutually dependent (Fig. 1C). The recruitment of phos- phorylated ATM (pATM) to DSBs following I-PpoI induction was unaffected by the absence of either RB or E2F1 (Supplemental Fig. S1e). Western blot analysis shows that the difference in recruitment of the different factors to I-PpoI cut sites did not arise due to differences in HAER*-I-PpoI expression (Supplemental Fig. S1f). Moreover, and consistent with ATM activation being unaffected by RB or E2F1 status, I-PpoI induction stimulated the phosphorylation of p53 on Ser15, a direct target of ATM, to similar levels in all three cell lines (Supplemental Fig. S1f). These findings demonstrate that RB is recruited to DSBs dependent on E2F1 and ATM kinase activity.

We recently developed a knock-in mouse model in which the ATM/ATR phosphorylation site on E2F1 (Ser29 in mice) was mutated to alanine (Biswas et al. 2014). We showed that this mutation had little effect on the expression of E2F1 target genes but did impair the association of E2F1 with UV-induced damage and nucleotide excision repair (NER) efficiency (Biswas et al. 2014). Using primary MEFs derived from wild-type and $E 2 f 1^{\text {S29A/S29A }}$ mice, we found that E2F1 was recruited to sequences flanking an I-PpoI-induced cut site on mouse chromosome 10 in wild-type MEFs but not in 
E2f1 ${ }^{\text {S29A/S29A }}$ MEFs, thus showing that the S29A knock-in mutation prevents recruitment of E2F1 to DSBs (Fig. 2A). Moreover, recruitment of RB to the induced DSB was also abolished in E2f1 ${ }^{S 29 A / S 29 A}$ MEFs, while enrichment of $\gamma \mathrm{H} 2 \mathrm{AX}$ at the cut site was unaffected by the E2F1 S29A mutation (Fig. 2B,C). E2F1 and RB protein levels were similar in wild-type and $E 2 f 1^{S 29 A / S 29 A}$ mutant cells before and after I-PpoI induction (Supplemental Fig. S2a). Occupancy of E2F1, RB, and $\gamma \mathrm{H} 2 \mathrm{AX}$ at the control Gapdh locus was unaffected by I-PpoI induction or the S29A mutation (Supplemental Fig. S2b-d). These findings demonstrate that $\mathrm{RB}$ recruitment to DSBs requires E2F1 Ser29, a site phosphorylated by ATM.

Phosphorylation of E2F1 at S29 creates a binding site for the sixth BRCT domain of TopBP1, and this interaction is known to be necessary for the recruitment of E2F1 to DSB sites (Liu et al. 2003). Consistent with this, a purified GST fusion protein containing the first six BRCT domains of TopBP1 was able to pull down E2F1 from IR-treated

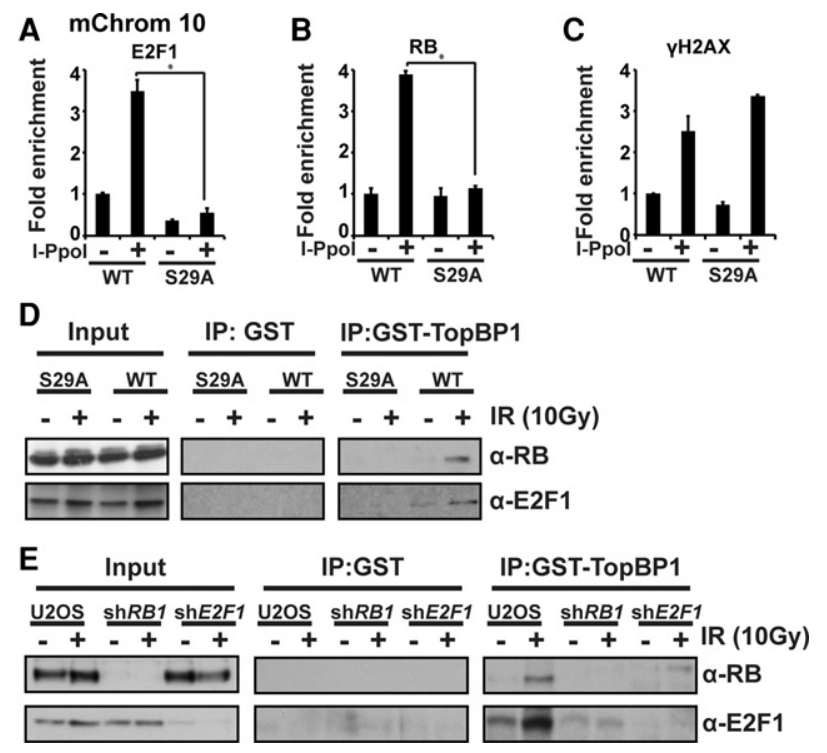

Figure 2. E2F1 S29A mutation prevents recruitment of RB to DSBs. $(A-C)$ Primary wild-type and E2f1 ${ }^{S 29 A / S 29 A}$ MEFs were uninfected $(-)$ or infected $(+)$ with a retrovirus expressing HA-ER*-IPpoI and treated with $2 \mu \mathrm{M}$ tamoxifen for $12 \mathrm{~h}$. ChIP was then performed, and occupancy of E2F1 $(A), \mathrm{RB}(B)$, and $\gamma \mathrm{H} 2 \mathrm{AX}(C)$ was determined by qPCR at the mouse chromosome 10 locus (269 bp $5^{\prime}$ to the I-PpoI cut site). Fold enrichment represents the ratio between the percentage of input of treated cells and untreated cells. $(D)$ Purified GST-TopBP1 (BRCT1-6) or GST control protein was incubated with whole-cell extract from wildtype or E2f1 ${ }^{S 29 A / S 29 A}$ MEFs that were either untreated or treated with 10 Gy of IR and harvested $2 \mathrm{~h}$ after IR. Associated proteins were pulled down using glutathione beads, and Western blot was performed using antibodies against RB and E2F1. (E) A GSTTopBP1 pull-down assay similar to that described above was performed using extracts from parental U2OS cells or U2OS cells knocked down for RB or E2F1 either untreated or treated with 10 Gy of IR and harvested $2 \mathrm{~h}$ after IR. All experiments were done in triplicate, and immunoblots are representative. Graphs represent averages $\pm \mathrm{SD}$. $\left(^{*}\right) P<0.05$. wild-type MEF extracts, while very low levels were obtained in the absence of DNA damage (Fig. 2D). In contrast, GST-TopBP1 was unable to pull down E2F1 from IR-treated extracts made from E2f1 $1^{S 29 A / S 29 A}$ cells even though similar levels of E2F1 protein were expressed in wild-type and E2f1 ${ }^{S 29 A / S 29 A}$ cells (Fig. 2D). Importantly, RB was also pulled down by GST-TopBP1 using IR-treated extracts derived from wild-type MEFs or parental U2OS cells (Fig. 2D,E). RB association with TopBP1 was dependent upon E2F1 and E2F1 phosphorylation, since it was abolished by the E2F1 S29A knock-in mutation, E2F1 depletion, or ATM inhibition (Fig. 2D,E; Supplemental Fig. S2e). Taken together, these findings support a model in which ATM-dependent phosphorylation of E2F1 and its association with TopBP1 recruit not only E2F1 but also RB to DSBs. Of note, the GST-TopBP1 pull-down experiments also showed the mutual dependence of $\mathrm{RB}$ and E2F1 for the stability of this interaction (Fig. 2E). $\mathrm{RB}$ stabilizes the TopBP1-E2F1 interaction by shielding phosphorylated E2F1 from proteasomal degradation, since this defect can be rescued by a proteasome inhibitor (Supplemental Fig. S2f). This finding is consistent with previous reports showing that $\mathrm{RB}$ protects $\mathrm{E} 2 \mathrm{~F} 1$ from proteasomal degradation (Hofmann et al. 1996; Campanero and Flemington 1997).

\section{$R B$ and E2F1 promote $\gamma H 2 A X$ clearance, $D N A$ end resection, and $H R$}

Since RB is recruited to DSBs, we sought to determine the effect of RB depletion on the repair of DSBs by monitoring the formation and disappearance of $\gamma \mathrm{H} 2 \mathrm{AX}$ foci following IR. RB-deficient U2OS cells displayed higher numbers (even without IR) of $\gamma \mathrm{H} 2 \mathrm{AX}$ foci after IR compared with parental U2OS cells, and these foci persisted longer in RB-deficient cells (Fig. 3A,B). On the other hand, the formation and kinetics of IR-induced 53BP1 foci was unaffected by the absence of RB (Fig. 3A,C). Western blot analysis confirmed that $\mathrm{RB}$ depletion in $\mathrm{U} 2 \mathrm{OS}$ cells resulted in higher levels of $\gamma \mathrm{H} 2 \mathrm{AX}$ that persisted longer following IR treatment (Supplemental Fig. S3a), indicating a defect in DSB repair in cells lacking RB.

As the E2F1 S29A mutation abolished the recruitment of RB to DSBs, we sought to determine whether this mutation would have the same effect as depletion of $\mathrm{RB}$ in repair. Like RB-deficient cells, E2f1 ${ }^{S 29 A / S 29 A}$ cells had higher numbers of $\gamma \mathrm{H} 2 \mathrm{AX}$ foci and delayed clearance kinetics compared with wild-type cells (Fig. 3D). Similar results were observed when Western blot analysis was used to examine $\gamma \mathrm{H} 2 \mathrm{AX}$ levels (Supplemental Fig. S3b). To further confirm that the E2F1 S29A mutation results in impaired DSB repair, MEFs from E2f1 $1^{S 29 A / S 29 A}$ and wild-type control mice were treated with the radiomimetic drug neocarzinostatin (NCS) and subjected to the single-cell gel electrophoresis (Comet) assay. As was observed with E2f1-/- cells (Chen et al. 2011), increased levels of DNA breaks were observed in E2f1 ${ }^{S 29 A / S 29 A}$ cells compared with wild-type cells before treatment and at later time points following NCS treatment (Fig. 3E). These findings indicate that either the absence of RB or blocking the 
A
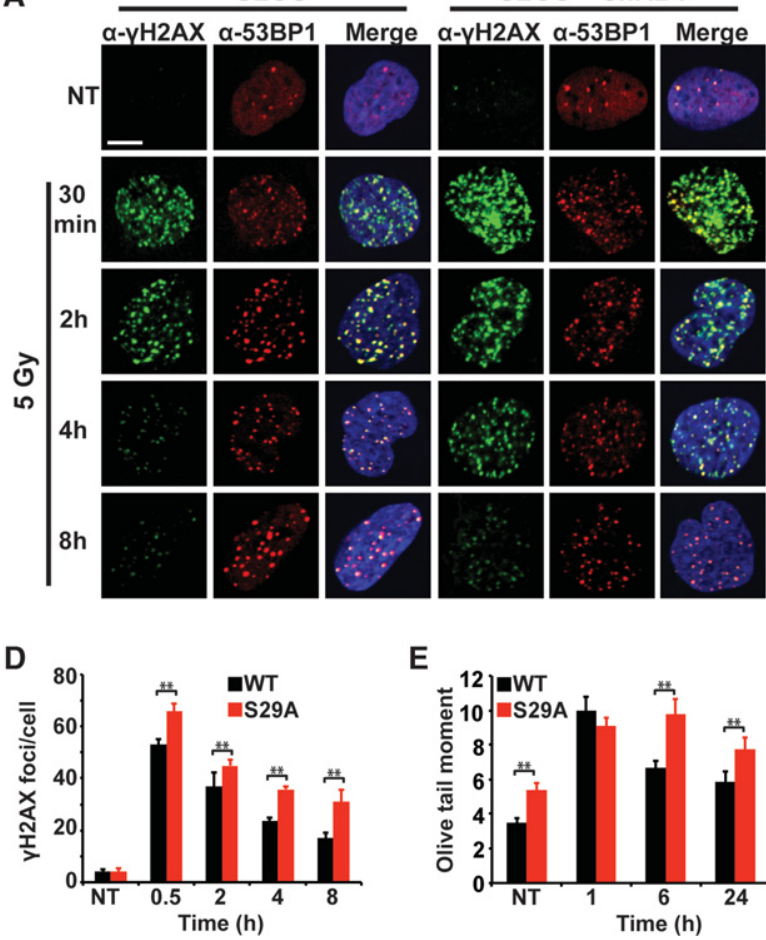

E

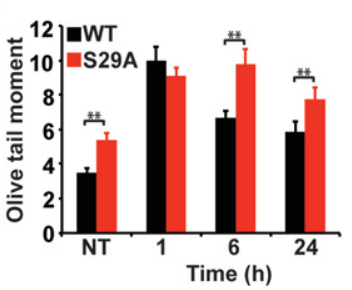

B

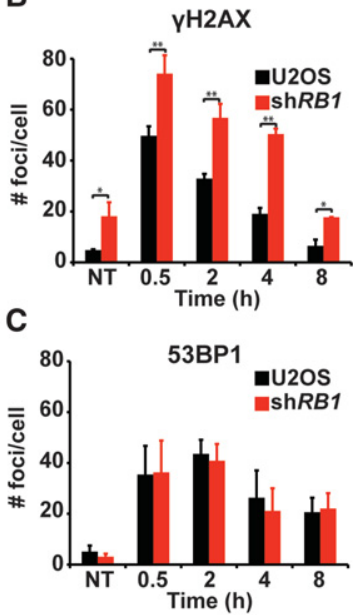

Figure 3. RB-deficient and E2F1 S29A cells are impaired for $\gamma \mathrm{H} 2 \mathrm{AX}$ clearance following IR. (A) Parental U2OS cells and U2OS cells expressing shRNA against RB $(+\operatorname{sh} R B 1)$ were mock-treated $(\mathrm{NT})$ or treated with 5 Gy of IR and allowed to repair DNA damage for the indicated times. Representative confocal microscopy images show the formation and disappearance of $\gamma \mathrm{H} 2 \mathrm{AX}$ (green) and 53BP1 (red) foci and colocalization (yellow; merge). Nuclei were counterstained with DAPI (blue). Bar, $10 \mu \mathrm{m}$. Quantification of $\gamma \mathrm{H} 2 \mathrm{AX}(B)$ and 53BP1 $(C)$ foci at the indicated times after IR was performed. $(D) \gamma \mathrm{H} 2 \mathrm{AX}$ foci formation and clearance were measured as above using primary wild-type and E2f1 $1^{S 29 A / S 29 A}$ MEFs. (E) Wild-type and $E 2 f 1^{S 29 A / S 29 A}$ MEFs were treated with the radiomimetic drug neocarzinostatin (NCS) for $30 \mathrm{~min}$ and incubated in fresh culture medium for the indicated times before subjecting cells to the single-cell electrophoresis (Comet) assay. The average Olive moment was determined. All experiments were done in triplicate. Graphs represent averages \pm SD. $\left(^{*}\right) P<0.05 ;\left(^{* *}\right) P<0.01$.

recruitment of RB to DSBs through the E2F1 S29A mutation results in a DSB repair defect.

While our studies showed that ATM activation was unaffected in the absence of RB (Supplemental Figs. S1d,e, S4a), ATR activation (monitored by the phosphorylation of the Chk1 kinase at Ser345) was attenuated in the absence of RB or E2F1 (Supplemental Fig. S4a). ATR activation is triggered by RPA-coated ssDNA regions generated through DNA end resection (Zou 2003). To directly measure the amount of ssDNA generated after IR through DNA end resection, we used an established method in which cells are allowed to incorporate BrdU, treated with IR, and then stained with an antibody against BrdU under nondenaturing conditions (Gospodinov et al. 2011). Because the antibody recognizes only BrdU within ssDNA, staining under nondenaturing conditions after IR detects primarily ssDNA generated through DNA end resection at DSBs. U2OS cells depleted for RB or E2F1 displayed reduced BrdU staining when compared with control U2OS cells, indicating a defect in the generation of ssDNA (Fig. 4A,B). Since these ssDNA regions are rapidly coated with RPA, we also analyzed RPA focus formation after IR in S/G2 cells (labeled by cyclin A expression). Depletion of RB significantly reduced the intensity of RPA foci after IR (Fig. 4A,C). We also observed impaired DNA end resection in RB- and E2F1-deficient cells using the chemotherapeutic drug camptothecin (CPT) to induce DSBs combined with a flow cytometry method to measure increases in chromatin-bound RPA after DNA damage in S/G2 cells (Supplemental Fig. S4b; Forment et al. 2012). A similar reduction in chromatin-bound RPA after CPT was also observed in $E 2 f 1^{S 29 A / S 29 A} \mathrm{MEFs}$, indicating that, similar to the absence of $\mathrm{RB}$ or $\mathrm{E} 2 \mathrm{~F} 1$, the $\mathrm{E} 2 \mathrm{~F} 1$
S29A mutation is sufficient to impair DNA end resection at DSBs (Fig. 4A-D).

Since DNA end resection is critical for HR repair, we used a widely used HR reporter system to test whether the absence of $\mathrm{RB}$ resulted in a defect in this repair pathway (Nakanishi et al. 2011). DR-U2OS cells have two differentially mutated GFP genes integrated in the genome. The first GFP has a recognition sequence for the I-SceI restriction enzyme where a DSB can be induced upon the transient expression of this enzyme. The second GFP gene can be used through HR to repair the first GFP fragment and restore GFP expression, and the efficiency of this HR event can be quantified by flow cytometry. DRU2OS cells were transfected with scrambled siRNAs or siRNAs against RB, E2F1, or both or against the DNA end resection endonuclease CtIP and, $72 \mathrm{~h}$ later, were transfected with a plasmid that expressed I-SceI. We observed that siRNAs efficiently reduced the levels of RB and E2F1 (Supplemental Fig. S4c), and flow cytometry analysis showed that depletion of either RB or E2F1 significantly reduced HR efficiency (Fig. 4E). Very similar results were obtained with a different set of siRNAs (Fig. 4E; Supplemental Fig. S4d,e). Of note, knocking down both $\mathrm{RB}$ and E2F1 did not result in further reduction in HR efficiency, thus supporting a model in which these proteins work within the same pathway in the repair of DSBs. Importantly, cell cycle analysis did not show major differences in cells depleted for RB or E2F1 (Supplemental Fig. S4c), thus demonstrating that the HR defect observed in the absence of RB or E2F1 is not due to indirect cell cycle effects.

In order to determine whether the E2F1 S29A mutation also affects HR, we used male mice and prepared 
A
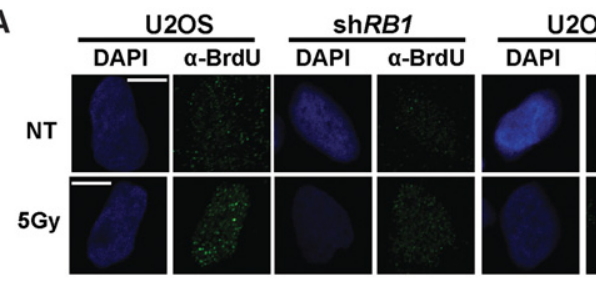

B
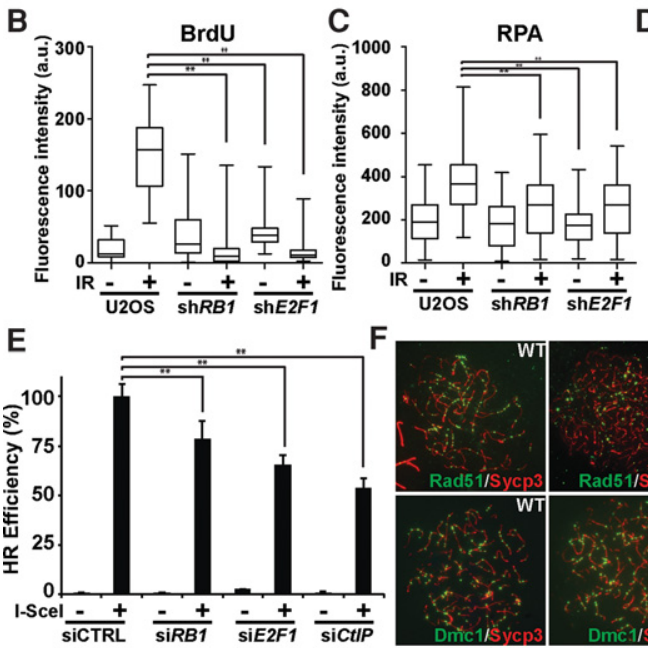

G
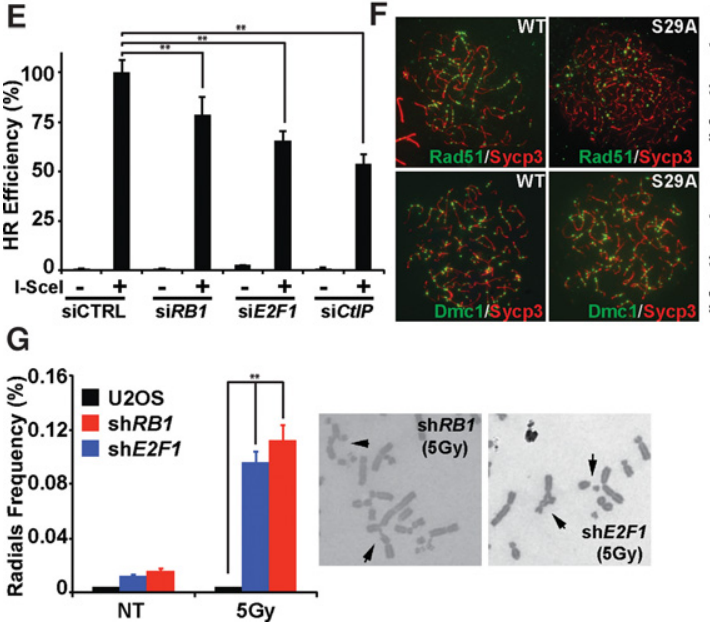

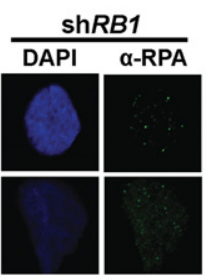

D
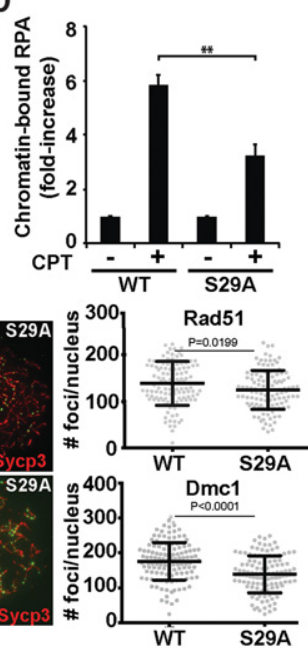

S29A spermatocyte spreads to analyze meiotic recombination progression. Meiotic recombination shares various proteins and processes with mitotic HR repair (Hunter 2015). As shown in Figure 4F, the strand exchange factors Rad51 and Dmc1, which form nucleoprotein filaments at resected meiotic DSBs, were significantly reduced in E2f1 $229 \mathrm{~A} / \mathrm{S} 29 \mathrm{~A}$ spermatocytes when compared with those of wild-type mice. This deficiency, observed in a physiological setting, further indicates that the E2F1-S29A mutation is sufficient to cause a defect in DNA end resection and HR.

HR is the less mutagenic DSB repair pathway (West 2003; Aparicio et al. 2014). Indeed, cells that are deficient in HR display higher levels of chromosomal aberrations after IR (West 2003; Aparicio et al. 2014). Thus, we sought to test whether the absence of RB or E2F1 would result in increased chromosomal aberrations after IR. U2OS control cells and cells expressing shRNAs against RB and E2F1 were treated with IR, and metaphase spreads were prepared $48 \mathrm{~h}$ later. As seen in Figure 4G, RB- and E2F1-deficient cells displayed increased frequency of chromosomal radials, breaks, and fusions after IR, indicating a defect in DSB repair. E2f1 $1^{S 29 A / S 29 A}$ fibroblasts also showed increased numbers of chromosomal breaks and fusions after IR treatment compared with wild-type MEFs (Supplemental Fig. S4f). Taken together, our data show that RB rate were mock-treated (NT) or treated with 5 Uy cells and, after 48 h, metaphase chromosomal radials were counted. Representative metaphase spreads are shown with arrows pointing to chromosomal breaks and radials. All experiments were done in triplicate. Graphs represent averages \pm SD. $(* *) P<0.01$.

Figure 4. RB and E2F1 deficiency results in defective DNA end resection and HR. (A) Parental U2OS cells and U2OS cells expressing shRNA against $R B 1$ or E2F1 were preincubated with BrdU and then mocktreated (NT) or treated with 5 Gy of IR and allowed to repair DNA damage for $3 \mathrm{~h}$. Representative confocal microscopy images stained against BrdU (left panels; green) or RPA (right panels; green) and focus formation were assessed $3 \mathrm{~h}$ after IR. Cyclin A-positive cells are shown. Bar, $10 \mu \mathrm{m}$. Fluorescence intensity of $\operatorname{BrdU}(B)$ and RPA $(C)$ foci was determined. $(D)$ Wild-type and E2f1 ${ }^{\text {S29A/S29A }}$ MEFs were mock-treated or treated with $1 \mu \mathrm{M}$ CPT for $1 \mathrm{~h}$ and immunofluorescently stained for RPA. The increase in the amount of chromatinbound RPA upon CPT treatment in S/G2 cells was measured by flow cytometry. (E) DR-U2OS cells were transfected with a scrambled siRNA (siCTRL) or siRNA targeting RB, E2F1, or CtIP (siRB1, siE2F1, or siCtIP) and, after $72 \mathrm{~h}$, were transfected with an empty plasmid $(-)$ or a plasmid expressing the I-SceI endonuclease $(+)$. After 48 h, GFP expression was measured by FACS to assess HR efficiency. Results were normalized as siCTRL $(+)$ equal to $100 \%$. (F) Representative spermatocyte chromosome spreads from various meiosis prophase I stages, stained for the indicated proteins. Quantification of total foci per nucleus in wild-type and E2f1 ${ }^{S 29 A / S 29 A}$ spermatocytes. Each dot is the count from a single nucleus. Error bars indicate mean \pm SD. ad51 and Dmc1 at early zygonema. (G) U2OS cells .

and E2F1 promote DNA end resection, and their absence causes a defect in HR that results in increased chromosomal aberrations after IR.

The DNA end resection step of HR is cell cycle-regulated and occurs primarily during the S and G2 phases of the cell cycle due to the need of a sister chromatid for HR to occur (Jasin and Rothstein 2013; Price and D'andrea 2013). Cell cycle analysis of U2OS cells expressing shRNAs against RB or E2F1 showed no major differences between the parental cell lines (Supplemental Fig. S4g). Furthermore, the levels of proteins involved in DNA end resection and $\mathrm{HR}$ were unaffected by knocking down $\mathrm{RB}$ or E2F1 (Supplemental Fig. S4h). Taken together, these findings indicate that the absence of either RB or E2F1 impairs DNA end resection and $H R$, and this defect is not due to indirect effects on cell cycle kinetics or expression of DNA repair factors. These findings also extend to E2f1 ${ }^{\text {S29A/S29A }}$ MEFs, which also display a defect in DNA end resection and increased chromosomal abnormalities after IR. A caveat in the case of the S29A MEFs is that cell cycle analysis of these MEFs showed modest cell cycle differences when compared with wild-type MEFs. Therefore, cell cycle differences could contribute to the defect in DNA end resection observed in these cells (Supplemental Fig. S4i). 
$R B$ and E2F1 promote DNA end resection and $H R$ through the recruitment of BRG1 to DSBs

DNA end resection entails the processing of DNA ends, which has been shown to be modulated by chromatin remodelers that can alter nucleosomes near the site of the break to allow the resection process to occur (Huertas et al. 2009; Chen and Symington 2012; Adkins et al. 2013; Price and D'andrea 2013; Gursoy-Yuzugullu et al. 2016). BRG1 is a catalytic subunit of the SWI/SNF family of ATPases that has been shown to interact with RB in the context of transcriptional repression (Dunaief et al. 1994; Strobeck et al. 2000; Kang et al. 2004; Liu et al. 2004) and also to be recruited to DSBs (Kakarougkas et al. 2014; Gong et al. 2015; Qi et al. 2015). We found that while the BRG1 ATPase is recruited to DSBs in control U2OS cells, it was not recruited in cells depleted for either RB or

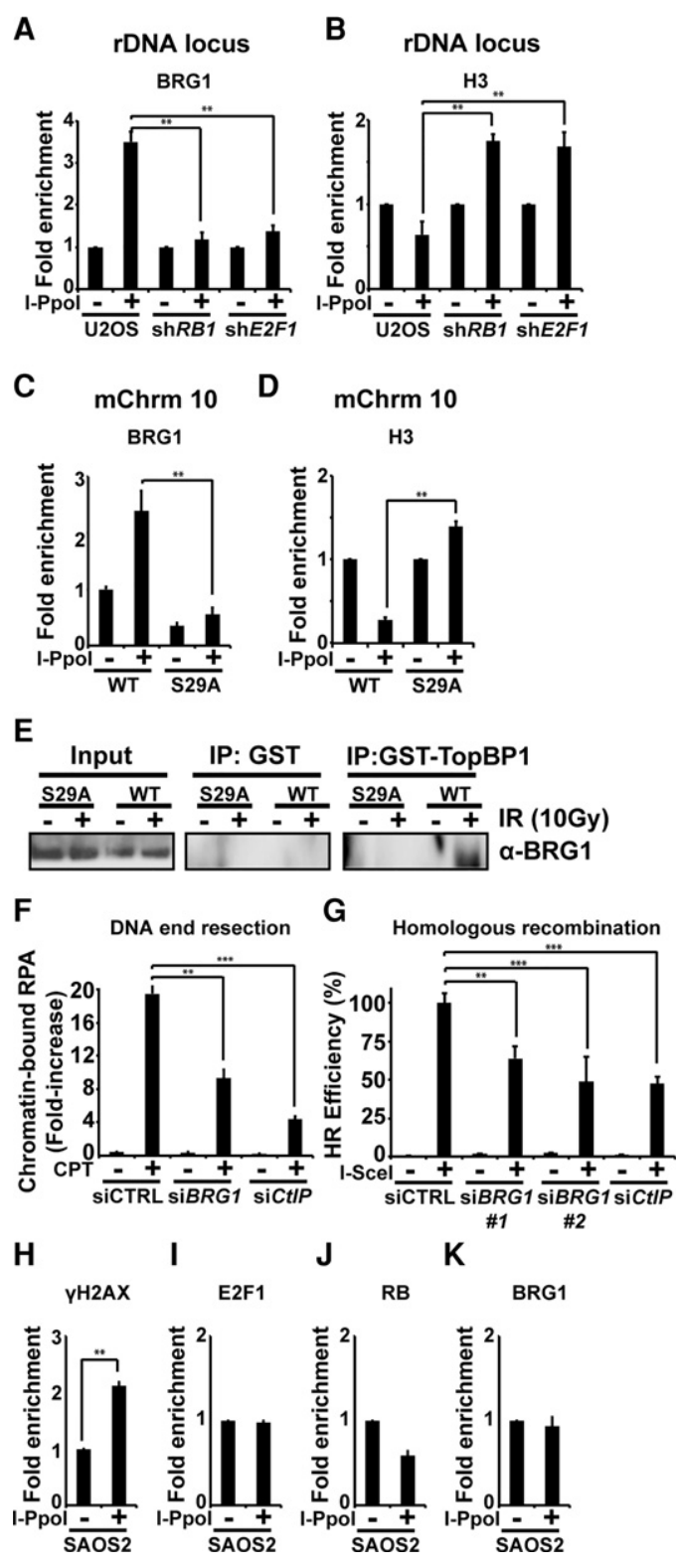

E2F1 (Fig. 5A). No differences in BRG1 recruitment were observed at the control GAPDH locus (Supplemental Fig. S5a). Also, similar BRG1 proteins levels were detected in all cell lines (Supplemental Fig. S5e). Since members of the SWI/SNF family of chromatin remodelers have been shown to affect nucleosome density, we tested whether histone $\mathrm{H} 3$ occupancy at the DSB was affected in cells in which the recruitment of BRG1 was impaired. As shown in Figure 5B, histone H3 occupancy at DSBs was slightly decreased in control cells, and this decrease was not observed in RB- and E2F1-deficient cells.

Recruitment of BRG1 to DSBs was also examined in wild-type and $E 2 f 1^{S 29 A / S 29 A}$ MEFs using the I-PpoI system. BRG1 was recruited to DSBs in wild-type MEFs but not in

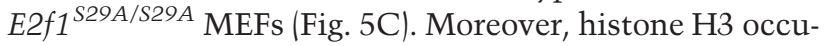
pancy was also decreased in wild-type MEFs, and this decrease was not observed in E2f1 ${ }^{S 29 A / S 29 A} \mathrm{MEFs}$, once again suggesting that the absence of BRG1 recruitment results in increased nucleosome density at DSBs. No differences were observed at the control Gapdh locus in either of the MEF lines (Supplemental Fig. S5c,d). The protein levels of BRG1 were also similar between wild-type and

Figure 5. RB and E2F1 recruit BRG1 to DSBs, and BRG1 stimulates DNA end resection and HR. (A) Parental U2OS cells and cells expressing $\operatorname{sh} R B 1$ or shE2F1 were mock-treated (-) or infected $(+)$ with a retrovirus expressing HA-ER*-I-PpoI and treated with $2 \mu \mathrm{M}$ tamoxifen for $12 \mathrm{~h}$. ChIP was performed using an antibody against BRG1 $(A)$ or $\mathrm{H} 3(B)$ and PCR primers at 489 bp $3^{\prime}$ of the IPpoI cut site at the $r D N A$ locus. Occupancy of BRG1 and H3 was determined by qPCR. Fold enrichment was expressed as above. (C) Primary wild-type and E2f1 $1^{S 29 A / S 29 A}$ MEFs were uninfected or infected with retrovirus expressing HA-ER*-I-PpoI and treated with $2 \mu \mathrm{M}$ tamoxifen for $12 \mathrm{~h}$. ChIP was performed using the indicated antibodies and PCR primers at $269 \mathrm{bp} 5^{\prime}$ to the I-PpoI cut site on mouse chromosome 10. Occupancy of BRG1 $(C)$ or H3 $(D)$ was determined by qPCR as above. (E) Purified GST-TopBP1 (BRCT1-6) or GST control protein was incubated with wholecell extract isolated from wild-type or E2f1 ${ }^{S 29 A / S 29 A}$ MEFs either mock-treated or treated with 10 Gy of IR for $2 \mathrm{~h}$. Associated proteins were pulled down using glutathione beads, and Western blot was performed on precipitated proteins using an antibody against BRG1. (F) U2OS cells were transfected with the indicated siRNAs and, at $72 \mathrm{~h}$, were treated with $1 \mu \mathrm{M} \mathrm{CPT}$ for $1 \mathrm{~h}$, permeabilized for $10 \mathrm{~min}$ in ice, fixed, and fluorescently stained for RPA (Forment et al. 2012). The increase in the amount of chromatinbound RPA upon DNA damage in S/G2 cells was measured by flow cytometry. ( $G$ ) DR-U2OS cells were transfected with the indicated siRNAs and, after $72 \mathrm{~h}$, were transfected with an empty plasmid $(-)$ or a plasmid expressing the ISceI endonuclease (+). After $48 \mathrm{~h}$, cells were harvested, and GFP expression was measured by flow cytometry to assess HR efficiency. $(H)$ SAOS-2 cells were mock-treated $(-)$ or infected $(+)$ with a retrovirus expressing HAER*-I-PpoI and treated with $2 \mu \mathrm{M}$ tamoxifen for $12 \mathrm{~h}$. ChIP was performed using antibodies against $\gamma \mathrm{H} 2 \mathrm{AX}(H), \mathrm{E} 2 \mathrm{~F} 1(I), \mathrm{RB}(J)$, or BRG1 $(K)$ and PCR primers at 489 bp $3^{\prime}$ of the I-PpoI cut site at the $r D N A$ locus. Occupancy of these different proteins was determined by qPCR. Fold enrichment was expressed as above. All experiments were done in triplicate. Graphs represent averages \pm SD. $\left(^{* *}\right) P<0.01 ;\left({ }^{* * *}\right) P<0.001$. Blots are representative of three independent experiments. 
E2f1 $1^{\text {S29A/S29A }}$ cells (Supplemental Fig. S5f). Importantly, like E2F1 and RB, GST-TopBP1 specifically pulled down BRG1 after DNA damage (Fig. 5E). These findings suggest that the ATM-mediated phosphorylation site of E2F1 and the binding site for TopBP1 are required for the recruitment of not only E2F1 and RB to DSBs but also BRG1 to DSBs.

In order to demonstrate that the defect in DNA end resection and HR observed in cells lacking RB and E2F1 stems from their defect in recruiting BRG1 to DSBs, we tested whether knocking down BRG1 would also result in the same defect as RB or E2F1 depletion. As shown in Figure 5F, U2OS cells transfected with siRNAs targeting BRG1 showed a defect in DNA end resection, as measured by a decreased amount of chromatin-bound RPA upon DNA damage in S/G2 cells when compared with cells transfected with scrambled siRNAs. Also, siRNAs targeting BRG1 resulted in a defect in HR efficiency, as measured using the DR-U2OS system (Fig. 5G). Taken together, our findings demonstrate that RB and E2F1 mediate the recruitment of the BRG1 ATPase to DSBs, and this chromatin remodeler is important for promoting efficient DNA end resection and HR. Our findings also suggest that BRG1 likely alters nucleosome density at DSBs to promote DNA end resection.

Germline mutations in the $\mathrm{RB} 1$ gene result in retinoblastomas in $>90 \%$ of the cases, but these patients also show increased incidence of other cancer types, such as osteosarcomas (Dyer 2016). In order to test whether a defect in BRG1 recruitment was also observed in cancer cells with $R B 1$ mutations, we used the I-PpoI system in a widely used osteosarcoma cell line (SAOS-2) that is known for its inactivation of RB. As shown in Figure 5, H-K, we observed enrichment of $\gamma \mathrm{H} 2 \mathrm{AX}$ upon the induction of DSBs but no recruitment of E2F1, RB, or BRG1. Taken together, these findings suggest that cancer cells with inactivated $R B 1$ mutations are unable to recruit BRG1 to DSBs.

$\mathrm{E} 2 \mathrm{f} 1^{\mathrm{S} 29 \mathrm{~A} / \mathrm{S} 29 \mathrm{~A}}$ mice are hypersensitive to $I R$, and $R B$-depleted cells are hypersensitive to DSB-inducing drugs

The $E 2 f 1^{S 29 A / S 29 A}$ mouse model provides a unique tool to study the in vivo importance of RB, E2F1, and BRG1 recruitment to DSBs without affecting the many other functions of RB and BRG1. Humans and mice that are defective in DSB repair are often hypersensitive to IR (West 2003; Aparicio et al. 2014). We therefore treated $E 2 f 1^{S 29 A / S 29 A}$ mice and wild-type sibling controls with 5.5 Gy of IR and then maintained them under sterile conditions. The majority of $E 2 f 1^{S 29 A / S 29 A}$ mice did not survive beyond $17 \mathrm{~d}$ following IR treatment, and all knockin mice had to be removed from the study by day 32 (Fig. 6A). On the other hand, $80 \%$ of wild-type siblings survived for $>2$ mo with no apparent signs of ill health. The acute apoptotic response in IR-sensitive tissues (intestines and thymus) was similar between E2f1 $229 \mathrm{~A} / \mathrm{S} 29 \mathrm{~A}$ and control mice, as was the inhibition of DNA synthesis, indicating that hypersensitivity to IR is not related to impaired apoptosis or G1/S-phase checkpoint responses
A

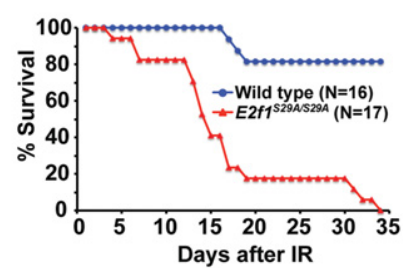

B
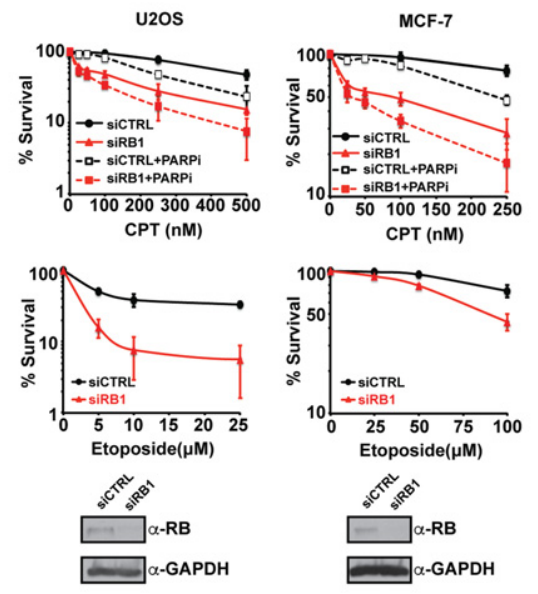

C

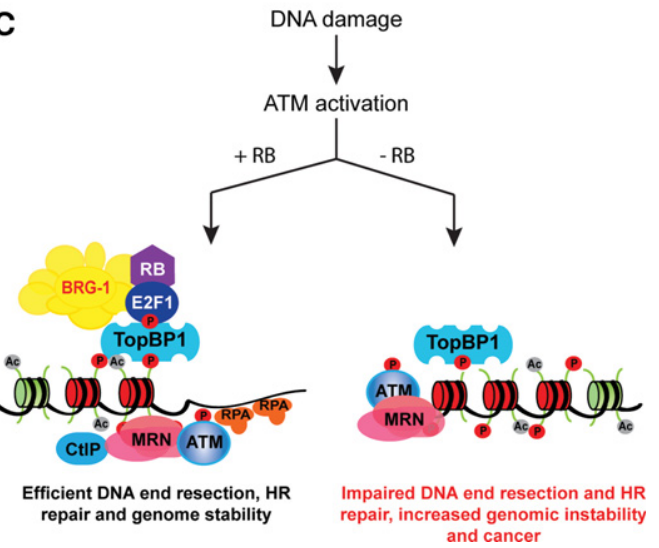

Figure 6. $E 2 f 1^{S 29 A / S 29 A}$ mice are hypersensitive to IR, and RB-depleted cells are hypersensitive to DSB-inducing drugs. (A) Young adult wild-type $(n=16)$ and $E 2 f 1^{S 29 A / S 29 A}(n=17)$ mice were exposed to 5.5 Gy of IR once, and their survival was monitored daily. A highly statistically significant difference in survival was observed between genotypes $(P<0.0001)$, as determined by the Kaplan-Meier survival method and log rank test. $(B)$ U2OS and MCF-7 cells were transfected with either scrambled siRNA (siCTRL; black circles) or siRNA against RB (siRB1; red triangles) and, at $72 \mathrm{~h}$, were treated with increasing concentrations of CPT in the presence or absence of $1 \mu \mathrm{M}$ PARP inhibitor olaparib (PARPi) or etoposide chemotherapeutic agents for $3 \mathrm{~d}$, after which cell survival was measured by the MTT assay. Graphs represent the averages of three independent experiments \pm SD. $(C)$ Schematic model for the recruitment and function of RB at DSBs. DNA damage activates the ATM kinase, which phosphorylates E2F1, and phosphorylated E2F1 is recruited to DSBs through its interaction with TopBP1. E2F1 in turn recruits RB, which stabilizes the TopBP1-E2F1 interaction and recruits BRG1. The BRG1 ATPase likely reduces nucleosome density at the DSB, which could stimulate resection by the DNA end resection machinery, thus promoting genomic stability. The absence of RB results in a DNA end resection and HR defect and genome instability. 
(Supplemental Fig. S6a,b). This finding underscores the importance of this newly uncovered role for $\mathrm{RB}$ and E2F1 in DSB repair, since impairing this function specifically results in reduced survival in mice.

$\mathrm{RB}$ loss is a hallmark of cancer and occurs at different frequencies in different cancer types. In order to test whether our findings could have a clinical application, we tested whether down-regulation of RB could sensitize cancer cells to chemotherapeutic agents that damage DNA (Fig. 6B). U2OS osteosarcoma cells and MCF-7 breast cancer cells were sensitized to the chemotherapeutic agents CPT and etoposide when RB was knocked down, in agreement with $\mathrm{RB}$ playing a role in the repair of DSBs. Moreover, simultaneous treatment of these cells with the PARP inhibitor olaparib and CPT resulted in further sensitization upon silencing of RB (Fig. 6B). These findings may prove useful in a clinical setting where $\mathrm{RB}$ status may be used to decide a chemotherapeutic regimen.

\section{Discussion}

In this study, we uncovered a novel, nontranscriptional function for RB in the repair of DNA DSBs that can help explain the genome instability observed in RB-deficient malignancies. This novel function for RB could also help explain the sensitivity of retinoblastomas to DSB-inducing drugs (Knudsen and Knudsen 2008; Witkiewicz et al. 2012; Thangavel et al. 2014). We show that RB is recruited to DSBs in an ATM- and E2F1-dependent manner and that the loss of $\mathrm{RB}$ results in a HR defect. $\mathrm{RB}$ is also required for the stabilization of the TopBP1-E2F1 interaction and the recruitment of the BRG1 ATPase to DSBs. We propose that BRG1 remodels chromatin at the break site likely by reducing nucleosome density, which may in turn stimulate the generation of ssDNA through DNA end resection, consequently promoting HR (Fig. 6C). Furthermore, the HR defect in RB-deficient cells results in increased chromosomal aberrations and genome instability, a hallmark of cancer associated with tumor aggressiveness and poor prognosis (Burrell et al. 2013).

The recruitment of $\mathrm{RB}$ to DSBs depends on its interaction with phosphorylated E2F1, which in turn interacts with TopBP1. TopBP1 itself is known to localize to DSBs through additional phospho-specific interactions with other repair proteins, such as MDC1, 53BP1, and BRIT1 (Cescutti et al. 2010; Wang et al. 2011; Zhang et al. 2014). This phosphorylation site on E2F1 is not conserved in other members of the E2F family of transcription factors (Liu et al. 2003). Indeed, previous work from our laboratory showed that phosphorylation at this site is also important for the recruitment of E2F1 to sites of UV damage and promotes the recruitment of the GCN5 HAT and NER factors to UV-damaged DNA (Guo et al. 2010, 2011). Furthermore, E2f1 ${ }^{S 29 A / S 29 A}$ mice are defective in NER and display higher incidence of UV-induced skin tumors (Biswas et al. 2014). We also showed previously that E2F1 was recruited to DSBs and that E2F1-deficient cells were impaired in the repair of this type of damage (Chen et al. 2011). Here we show that phosphorylated E2F1 in turn recruits $\mathrm{RB}$ to DSBs and that RB itself is im- portant for the stability of the TopBP1-E2F1 interaction. The interaction between RB and phosphorylated E2F1 shields phosphorylated E2F1 from ubiquitination and proteasomal degradation, since treatment of RB-deficient cells with the proteasomal inhibitor MG132 restored normal levels of phosphorylated E2F1 after IR. This shielding role for RB has been shown previously for total E2F1 (Hofmann et al. 1996; Campanero and Flemington 1997).

We show here that RB-deficient cells and E2f1 ${ }^{S 29 A / S 29 A}$ MEFs are defective in DSB repair, specifically in HR. The importance of HR is underscored by studies showing that cells with defective DNA repair display genomic instability (Aparicio et al. 2014). Genomic instability has been shown to promote tumor heterogeneity, loss of heterozygosity of tumor suppressor genes, and worse prognoses (Burrell et al. 2013). RB-deficient cells have been shown to be sensitive to DNA damage, and this sensitivity had been ascribed previously to the G1/S checkpoint defect. Our findings provide an additional explanation for this sensitivity.

How, exactly, is RB promoting DNA end resection and HR? Chromatin structure is known to be a major barrier to DNA end resection, and chromatin remodelers can modulate this process (Gospodinov et al. 2011; Chen and Symington 2012; Price and D'andrea 2013). We show here that the loss of $\mathrm{RB}$ results in defective recruitment of the BRG1 ATPase to DSBs, and, accordingly, this defect was also observed in E2f1 $229 A / S 29 A$ MEFs. While the involvement of BRG1 in DNA damage signaling and repair has been described previously (Kakarougkas et al. 2014; Gong et al. 2015; Qi et al. 2015), the mechanism by which this ATPase is recruited to DSBs has been elusive. It is important to note that the interaction between RB and BRG1 has long been described in the context of transcriptional repression (Dunaief et al. 1994; Strobeck et al. 2000; Kang et al. 2004; Liu et al. 2004; Flowers et al. 2013). Here we provide evidence that RB is directly involved in the recruitment of BRG1 to DSBs. BRG1 and other ATPases, such as p400 and INO80, are known to play a role in DNA end resection and HR $(\mathrm{Xu}$ et al. 2010; Gospodinov et al. 2011; Alatwi and Downs 2015; Gursoy-Yuzugullu et al. 2015). In this study, we show that depletion of BRG1 impaired DNA end resection and HR. This ATPase is known for its capacity to slide or push nucleosomes within DNA at gene promoters and enhancers to either allow or block access of transcription factors to DNA by changing nucleosome density (Wilson and Roberts 2011). We propose that BRG1-mediated nucleosome remodeling at DSBs helps to alleviate the barrier that nucleosomes pose to the DNA processing enzymes involved in the resection process. It is possible that BRG1 may be recruited to DSBs through different mechanisms depending on the chromatin environment at the break (Gursoy-Yuzugullu et al. 2016). Given the importance of DNA end resection and HR in preserving genome integrity, it is likely that this novel repair function for RB could contribute to the genomic instability reported in RB-negative malignancies. A recent report showed also that RB directly interacts with components of the NHEJ pathway (Cook et al. 2015). 
Chromatin and the factors that modify its structure play important roles in transcriptional regulation, and it has been shown lately to also play a critical role in DNA repair. Similarly, the lines between transcription factors and repair factors have become more blurred. Several other transcription factors, including ATF2, FOXO3a, NR4A, and Sp1, are also known to localize to DSBs and directly stimulate DNA repair and/or checkpoint signaling independently of transcription (Bhoumik et al. 2005; Tsai et al. 2008; Malewicz et al. 2011; Beishline et al. 2012; Velez-Cruz and Johnson 2012; Malewicz and Perlmann 2014). Like E2F1, these other transcription factors localize to DSBs independently of their DNA-binding domains, but it is unclear whether they recruit histone-modifying or remodeling enzymes to alter chromatin structure at DSBs. If they do, this would establish a general paradigm in which the cellular machinery that regulates transcription and DNA repair share not only enzymes that directly alter chromatin structure but also transcription factors and coregulators that target these enzymes to specific loci. The identification of novel players in the repair of DSBs not only could help us better understand the repair process, but this information could help us devise improved therapies for cancer. In the case of RB, this novel, nontranscriptional function agrees with a more recent view of this tumor suppressor that describes it as a multifunctional chromatin-associated protein that controls many processes involved in carcinogenesis (Dyson 2016).

\section{Materials and methods}

\section{Cell lines}

U2OS cells were obtained from American Type Culture Collection and infected with lentiviral particles expressing shRNA targeting RB1 or E2F1. U2OS parental and shRNA-expressing cell lines were maintained in DMEM supplemented with $10 \%$ FCS (Sigma) and antibiotics at $37^{\circ} \mathrm{C}$ in $5 \% \mathrm{CO}_{2}$. Wild-type and

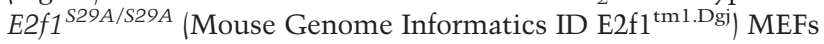
were maintained in DMEM supplemented with $15 \%$ heat-inactivated FCS, antibiotics, and $0.1 \mathrm{mM} \beta$-mercaptoethanol under low-oxygen conditions. IR treatments were performed with an RS-2000 biological irradiator (Rad Source). Where indicated, cells were treated with $1 \mu$ M ATM inhibitor KU-60019 (SelleckChem).

\section{Antibodies}

See Supplemental Table 1 for the antibodies used.

\section{Confocal microscopy}

Cells were seeded on a coverslip $24 \mathrm{~h}$ prior to the experiment. In situ extraction protocol was used for the visualization of RB foci (Mirzoeva and Petrini 2001). Cells were treated with the indicated doses of IR and, at the indicated times, rinsed with cold PBS, incubated for $5 \mathrm{~min}$ at $4^{\circ} \mathrm{C}$ in pre-extraction buffer $(25 \mathrm{mM}$ HEPES at $\mathrm{pH} 7.5,50 \mathrm{mM} \mathrm{NaCl}, 1 \mathrm{mM}$ EDTA, $3 \mathrm{mM} \mathrm{MgCl}_{2}, 300 \mathrm{mM}$ sucrose, $0.5 \%$ Triton $\mathrm{X}-100$ ), incubated for $5 \mathrm{~min}$ at $4^{\circ} \mathrm{C}$ in CSK buffer (10 mM Tris at $\mathrm{pH} 7.4,10 \mathrm{mM} \mathrm{NaCl}, 3 \mathrm{mM} \mathrm{MgCl}_{2}$, $1 \mathrm{mM}$ EDTA, $0.5 \%$ Triton X-100, 0.5\% Na-deoxycholate), fixed for $15 \mathrm{~min}$ at room temperature in 3\% formaldehyde (Sigma), permeabilized with $0.5 \%$ Triton X-100 (Sigma) for $5 \mathrm{~min}$, and blocked in 10\% FCS for 45 min. Coverslips were mounted in ProLong Gold with DAPI (Invitrogen), and pictures were taken using a Zeiss LSM880 confocal microscope (63× oil objective). Representative images are shown. Focus quantification was performed using ImageJ software, and at least 150 cells per time point were analyzed per experiment for the calculation.

\section{ChIP}

U2OS and MEF cells were transduced with a retrovirus expressing the HA-ER*-I-PpoI enzyme (Berkovich et al. 2007) twice to increase infection efficiency and treated with $2 \mu \mathrm{M}$ tamoxifen (Sigma) for $12 \mathrm{~h}$. Cells were harvested by adding formaldehyde ( $1 \%$ final concentration) followed by glycine at $1.25 \mathrm{mM}$ final concentration (Carey et al. 2009). Nuclear extracts were prepared and sonicated (Diagenode Bioruptor). Occupancy was measured by quantitative PCR (qPCR) using primers for the indicated loci (Berkovich et al. 2007). Each experiment was carried out in triplicate.

\section{GST pull-down and Western blot analysis}

Cells were treated as indicated and harvested in cold PBS followed by resuspension in cell lysis buffer $(20 \mathrm{mM}$ Tris at $\mathrm{pH} 7.5$, $150 \mathrm{mM} \mathrm{NaCl}, 1 \%$ Triton X-100, 1 mM EDTA, 0.5 mM EGTA, protease inhibitor cocktail, phosphatase inhibitor, $300 \mathrm{nM}$ TSA). Pull-down was performed using $1 \mathrm{mg}$ of extract and $15 \mu \mathrm{g}$ of purified GST or GST-TopBP1 and glutathione beads (Cell Signaling Technologies) following the manufacturer's directions. Samples were mixed with Leamili buffer, boiled for $5 \mathrm{~min}$, separated by SDS-PAGE, and visualized by ECL.

\section{ssDNA BrdU immunofluorescent staining}

Briefly, cells were incubated with $30 \mu \mathrm{g} / \mathrm{mL}$ BrdU for $36 \mathrm{~h}$, irradiated at $5 \mathrm{~Gy}$, and harvested at the indicated times as described previously (Gospodinov et al. 2011). Cells were treated as for RB foci and stained with anti-BrdU and anti-cyclin A antibodies (to label S/G2 cells). Images were taken on the confocal microscope (63× oil), and fluorescence intensity was measured in cyclin A-positive cells with ImageJ software.

\section{Comet assay}

The single-cell gel electrophoresis (Comet) assay was carried out using the Comet assay kit (Trevigen). Briefly, cells were exposed to NCS for $30 \mathrm{~min}$ and cultured in fresh medium for the indicated times prior to harvesting. Cells were then embedded in low-melting agarose on a glass slide and incubated overnight at $4^{\circ} \mathrm{C}$ in lysis buffer. Samples were washed and electrophoresed at $19 \mathrm{~V}$ for 5-20 min in TBE and stained with SYBR Green. Nuclei were visualized, and images were captured using a fluorescent microscope. Tail length and Olive moment (50 nuclei per slide) were calculated using CometScore software (Tritek).

\section{Chromatin-bound RPA by flow cytometry}

Briefly, cells were mock-treated or treated with $1 \mu \mathrm{M} \mathrm{CPT}$ for $1 \mathrm{~h}$ and harvested by trypsinization. Cells were permeabilized for $10 \mathrm{~min}$ in ice in T-PBS (PBS $+0.2 \%$ Triton X-100), fixed in $4 \%$ formaldehyde, and stained with an anti-RPA antibody. Cells were resuspended in an RNase A/PI solution, and FACS analysis was performed as described previously (Forment et al. 2012). The 
increase in chromatin-bound RPA in S/G2 cells upon CPT treatment was measured using FlowJo.

\section{HR efficiency}

DR-U2OS cells were transfected with $100 \mathrm{nM}$ control scrambled siRNAs or siRNAs against different proteins as indicated using Lipofectamine 2000 (Invitrogen). Seventy-two hours after transfection, cells were transfected with pCAB-ISceI plasmid using Fugene HD. Forty-eight hours after transfection, cells were harvested by trypsinization and resuspended in PBS, and flow cytometry was performed to monitor GFP-positive cells. Analysis was performed using FlowJo. A fraction of the cells was used to perform Western blot analysis.

\section{Spermatocyte chromosome spreads}

Spermatocytes from adult ( $\sim 5$-mo-old) mice were separated into individual cells in suspension before surface spreading as described previously (Cole et al. 2012). The antibodies used were SYCP3 (Santa Cruz Biotechnology), RAD51 (EMD), and DMC1 (Santa Cruz Biotechnology). After immunostaining, slides were mounted in ProLong Gold anti-fade reagent with DAPI (Invitrogen). Nuclei were staged by assessing the staining of SYCP3 with the following criteria: leptonema, short stretches of axis with no evidence of thickening associated with synapsis; early zygonema, longer cohesive stretches of axis and some synapsis; late zygonema, $>50 \%$ synapsed axes but not complete; and early pachynema, completely synapsed axes but less intensely stained sex body chromatin. The genotypes of the samples were blinded until after focus counts were determined. Only axis-associated foci were counted.

\section{Metaphase spread preparation}

Briefly, cells were treated as indicated and, $40 \mathrm{~h}$ after treatment, incubated with $3 \mathrm{ng} / \mathrm{mL}$ colcemid for $4 \mathrm{~h}$, put in a hypotonic solution $(0.075 \mathrm{M} \mathrm{KCl})$ for $10 \mathrm{~min}$, fixed (1:3 acetic acid:methanol), and spread on a slide as described previously (Owen et al. 2014). Pictures were taken with a $63 \times$ oil immersion objective (Olympus). Approximately 150 metaphases were counted per treatment per experiment.

\section{Cell cycle analysis}

Cell cycle analysis was performed using the EdU Click-iT kit (Invitrogen) following the manufacturer's direction. Cells were incubated for $2 \mathrm{~h}$ with $10 \mu \mathrm{M}$ EdU, fixed, and labeled with Alexa fluor 488, and DNA was labeled with Vybrant Violet (Invitrogen). Data collection was performed in a BD LSRFortessa, and analysis was performed in FlowJo.

\section{Cell survival assay}

Cells were seeded in 96-well plates and, 24 h later, treated with the indicated concentrations of the indicated drugs for $3 \mathrm{~d}$. On day 4, cell survival was assessed using CellTiter96 (Invitrogen).

\section{Statistical analysis}

All experiments were carried out in triplicate, and statistical analysis was performed in Prism 6 using the unpaired $t$-test analysis when comparing two samples and ANOVA when comparing more than two samples. Significance was determined, with
$P<0.05(*)$ considered to be significant, and $P<0.01(* *)$ considered to be highly significant.

\section{Mouse survival after IR}

Generation of the E2f1 ${ }^{S 29 A / S 29 A}$ knock-in mouse model was described elsewhere (Biswas et al. 2014). E2f1 $1^{S 29 A / S 29 A}$ mice and wild-type sibling controls were exposed to $5.5 \mathrm{~Gy}$ of IR and maintained under sterile conditions. Mice were monitored daily and sacrificed when moribund per federal and institutional guidelines.

\section{Acknowledgments}

We thank J. Smith Orona, P. Blau, and C. Sagum for expert technical assistance, and P. Whitney, C. Jeter, and the Science Park Flow Cytometry and Cell Imaging Facility. We also thank L. Coghlan, D. Weiss, and coworkers for animal care; F. Benavides and C. Perez for mouse genetic analysis; D. Kusewitt and N. Otto for histopathology; the University of Texas MD Anderson Cancer Center Cytogenetics Core Facility for metaphase chromosome analysis; and N. Owen (Oregon Health and Science University) for her expertise. We thank M. Jasin (Memorial Sloan Kettering Cancer Center) for providing us with the DR-U2OS cells, and K. Takata (MD Anderson Cancer Center) for the pCAB-ISceI plasmid. M. Bedford and S. Ray also provided helpful advice and input. This work was supported by the Cancer Prevention and Research Institute of Texas (R1213 to F.C., and RP140222 to D.G.J.), the National Institute of Health (grants CA079648 to D.G.J., and DP2HD087943 to F.C.), the Jeanne F. Shelby Scholarship Fund (F.C.), the R. Lee Clark Fellowship (F.C.), and a Cancer Core Support grant (CA016672). S.M. was supported by a fellowship from the Center for Cancer Epigenetics at University of Texas MD Anderson Cancer Center, and R.W.C. was supported by an American Legion Auxiliary Fellowship and a Cancer Answers/Sylvan Rodriguez Scholarship.

\section{References}

Adkins NL, Niu H, Sung P, Peterson CL. 2013. Nucleosome dynamics regulates DNA processing. Nat Struct Mol Biol 20: 836-842.

Alatwi HE, Downs JA. 2015. Removal of H2A.Z by INO80 promotes homologous recombination. EMBO Rep 16: 986994.

Aparicio T, Baer R, Gautier J. 2014. DNA double-strand break repair pathway choice and cancer. DNA Repair 19: 169-175.

Beishline K, Kelly CM, Olofsson BA, Koduri S, Emrich J, Greenberg RA, Azizkhan-Clifford J. 2012. Sp1 facilitates DNA double-strand break repair through a nontranscriptional mechanism. Mol Cell Biol 32: 3790-3799.

Berkovich E, Monnat RJ, Kastan MB. 2007. Roles of ATM and NBS1 in chromatin structure modulation and DNA doublestrand break repair. Nat Cell Biol 9: 683-690.

Bhoumik A, Takahashi S, Breitweiser W, Shiloh Y, Jones N, Ronai Z. 2005. ATM-dependent phosphorylation of ATF2 is required for the DNA damage response. Mol Cell 18: 577-587.

Biswas AK, Mitchell DL, Johnson DG. 2014. E2F1 responds to ultraviolet radiation by directly stimulating DNA repair and suppressing carcinogenesis. Cancer Res 74: 3369-3377.

Burrell RA, McGranahan N, Bartek J, Swanton C. 2013. The causes and consequences of genetic heterogeneity in cancer evolution. Nature 501: 338-345. 
Campanero MR, Flemington EK. 1997. Regulation of E2F through ubiquitin-proteasome-dependent degradation: stabilization by the pRB tumor suppressor protein. Proc Natl Acad Sci 94: 2221-2226.

Carey MF, Peterson CL, Smale ST. 2009. Chromatin immunoprecipitation (ChIP). Cold Spring Harb Protoc doi: 10.1101/pdb. prot5279.

Cescutti R, Negrini S, Kohzaki M, Halazonetis TD. 2010. TopBP1 functions with 53BP1 in the G1 DNA damage checkpoint. EMBO I 29: 3723-3732.

Chen H, Symington LS. 2012. Overcoming the chromatin barrier to end resection. Cell Res 23: 317-319.

Chen J, Zhu F, Weaks RL, Biswas AK, Guo R, Li Y, Johnson DG. 2011. E2F1 promotes the recruitment of DNA repair factors to sites of DNA double-strand breaks. Cell Cycle 10: 1287-1294.

Cole F, Kauppi L, Lange J, Roig I, Wang R, Keeney S, Jasin M. 2012. Homeostatic control of recombination is implemented progressively in mouse meiosis. Nature 14: 424-430.

Cook R, Zoumpoulidou G, Luczynski MT, Rieger S, Moquet J, Spanswick VJ, Hartley JA, Rothkamm K, Huang PH, Mittnacht S. 2015. Direct involvement of retinoblastoma family proteins in DNA repair by non-homologous end-joining. Cell Rep 10: 2006-2018.

Coschi CH, Martens AL, Ritchie K, Francis SM, Chakrabarti S, Berube NG, Dick FA. 2010. Mitotic chromosome condensation mediated by the retinoblastoma protein is tumor-suppressive. Genes Dev 24: 1351-1363.

Costelloe T, Louge R, Tomimatsu N, Mukherjee B, Martini E, Khadaroo B, Dubois K, Wiegant WW, Thierry A, Burma S, et al. 2012. The yeast Fun30 and human SMARCAD1 chromatin remodellers promote DNA end resection. Nature 489: 581-584.

Degregori J. 2011. A new role for E2F1 in DNA repair: all for the greater good. Cell Cycle 10: 1716.

Degregori J, Johnson DG. 2006. Distinct and overlapping roles for E2F family members in transcription, proliferation and apoptosis. Curr Mol Med 6: 739-748.

Dick FA, Dyson N. 2003. pRB contains an E2F1-specific binding domain that allows E2F1-induced apoptosis to be regulated separately from other E2F activities. Mol Cell 12: 639-649.

Dick FA, Rubin SM. 2013. Molecular mechanisms underlying RB protein function. Nat Rev Mol Cell Biol 14: 297-306.

Dunaief JL, Strober BE, Guha S, Khavari PA, Alin K, Luban J, Begemann M, Crabtree GR, Goff SP. 1994. The retinoblastoma protein and BRG1 form a complex and cooperate to induce cell cycle arrest. Cell 79: 119-130.

Dyer MA. 2016. Lessons from retinoblastoma: implications for cancer, development, evolution, and regenerative medicine. Trends Mol Med 22: 863-876.

Dyson NJ. 2016. RB1: a prototype tumor suppressor and an enigma. Genes Dev 30: 1492-1502.

Flowers S, Xu F, Moran E. 2013. Cooperative activation of tissuespecific genes by pRB and E2F1. Cancer Res 73: 2150-2158.

Forment JV, Walker RV, Jackson SP. 2012. A high-throughput, flow cytometry-based method to quantify DNA-end resection in mammalian cells. Cytometry 81: 922-928.

Gong F, Chiu L-Y, Cox B, Aymard F, Clouaire T, Leung JW, Cammarata M, Perez M, Agarwal P, Brodbelt JS, et al. 2015. Screen identifies bromodomain protein ZMYND8 in chromatin recognition of transcription-associated DNA damage that promotes homologous recombination. Genes Dev 29: 197-211.

Gonzalo S, García-Cao M, Fraga MF, Schotta G, Peters AHFM, Cotter SE, Eguía R, Dean DC, Esteller M, Jenuwein T, et al. 2005. Role of the RB1 family in stabilizing histone methyla- tion at constitutive heterochromatin. Nat Cell Biol 7: 420-428.

Gospodinov A, Vaissiere T, Krastev DB, Legube G, Anachkova B, Herceg Z. 2011. Mammalian Ino80 mediates double-strand break repair through its role in DNA end strand resection. Mol Cell Biol 31: 4735-4745.

Guo R, Chen J, Zhu F, Biswas AK, Berton TR, Mitchell DL, Johnson DG. 2010. E2F1 localizes to sites of UV-induced DNA damage to enhance nucleotide excision repair. $J$ Biol Chem 285: 19308-19315.

Guo R, Chen J, Mitchell DL, Johnson DG. 2011. GCN5 and E2F1 stimulate nucleotide excision repair by promoting $\mathrm{H} 3 \mathrm{~K} 9$ acetylation at sites of damage. Nucleic Acids Res 39: 1390-1397.

Gursoy-Yuzugullu O, Ayrapetov MK, Price BD. 2015. Histone chaperone Anp32e removes H2A.Z from DNA double-strand breaks and promotes nucleosome reorganization and DNA repair. Proc Natl Acad Sci 112: 7507-7512.

Gursoy-Yuzugullu O, House N, Price BD. 2016. Patching broken DNA: nucleosome dynamics and the repair of DNA breaks. I Mol Biol 428: 1846-1860.

Hanahan D, Weinberg RA. 2011. Hallmarks of cancer: the next generation. Cell 144: 646-674.

Hilgendorf KI, Leshchiner ES, Nedelcu S, Maynard MA, Calo E, Ianari A, Walensky LD, Lees JA. 2013. The retinoblastoma protein induces apoptosis directly at the mitochondria. Genes Dev 27: 1003-1015.

Hofmann F, Martelli F, Livingston DM, Wang Z. 1996. The retinoblastoma gene product protects E2F-1 from degradation by the ubiquitin-proteasome pathway. Genes Dev 10: 29492959.

Huertas D, Sendra R, Muñoz P. 2009. Chromatin dynamics coupled to DNA repair. Epigenetics 4: 31-42.

Hunter N. 2015. Meiotic recombination: the essence of heredity. Cold Spring Harb Perspect Biol 7: a016618.

Ianari A, Natale T, Calo E, Ferretti E, Alesse E, Screpanti I, Haigis K, Gulino A, Lees JA. 2009. Proapoptotic function of the retinoblastoma tumor suppressor protein. Cancer Cell 15: 184-194.

Inoue Y, Kitagawa M, Taya Y. 2007. Phosphorylation of pRB at Ser612 by Chk1/2 leads to a complex between pRB and E2F1 after DNA damage. EMBO I 26: 2083-2093.

Jasin M, Rothstein R. 2013. Repair of strand breaks by homologous recombination. Cold Spring Harb Perspect Biol 5: a012740.

Kakarougkas A, Ismail A, Chambers AL, Riballo E, Herbert AD, Künzel J, Löbrich M, Jeggo PA, Downs JA. 2014. Requirement for PBAF in transcriptional repression and repair at DNA breaks in actively transcribed regions of chromatin. Mol Cell 55: 723-732.

Kang H, Cui K, Zhao K. 2004. BRG1 controls the activity of the retinoblastoma protein via regulation of $\mathrm{p} 21 \mathrm{CIP} 1 / \mathrm{WAF} 1 /$ SDI. Mol Cell Biol 24: 1188-1199.

Knudsen ES, Knudsen KE. 2008. Tailoring to RB: tumour suppressor status and therapeutic response. Nat Rev Cancer 8: 714-724.

Liu Y, West SC. 2002. Distinct functions of BRCA1 and BRCA2 in double-strand break repair. Breast Cancer Res 4: 9-13.

Liu K, Lin F-T, Ruppert JM, Lin W-C. 2003. Regulation of E2F1 by BRCT domain-containing protein TopBP1. Mol Cell Biol 23: 3287-3304.

Liu K, Luo Y, Lin F-T, Lin W-C. 2004. TopBP1 recruits Brg1/Brm to repress E2F1-induced apoptosis, a novel pRb-independent and E2F1-specific control for cell survival. Genes Dev 18: 673-686. 
Malewicz M, Perlmann T. 2014. Function of transcription factors at DNA lesions in DNA repair. Exp Cell Res 329: 94-100.

Malewicz M, Kadkhodaei B, Kee N, Volakakis N, Hellman U, Viktorsson K, Leung CY, Chen B, Lewensohn R, van Gent DC, et al. 2011. Essential role for DNA-PK-mediated phosphorylation of NR4A nuclear orphan receptors in DNA double-strand break repair. Genes Dev 25: 2031-2040.

Manning AL, Longworth MS, Dyson NJ. 2010. Loss of pRB causes centromere dysfunction and chromosomal instability. Genes Dev 24: 1364-1376.

Mimitou EP, Symington LS. 2009. Nucleases and helicases take center stage in homologous recombination. Trends Biochem Sci 34: 264-272.

Mimitou EP, Symington LS. 2011. DNA end resection-unraveling the tail. DNA Repair 10: 344-348.

Mirzoeva OK, Petrini JH. 2001. DNA damage-dependent nuclear dynamics of the Mre11 complex. Mol Cell Biol 21: 281-288.

Nakanishi K, Cavallo F, Brunet E, Jasin M. 2011. Homologous recombination assay for interstrand cross-link repair. Methods Mol Biol 745: 283-291.

Owen N, Hejna J, Rennie S, Mitchell A, Hanlon Newell A, Ziaie N, Moses RE, Olson SB. 2014. Bloom syndrome radials are predominantly non-homologous and are suppressed by phosphorylated BLM. Cytogenet Genome Res 144: 255-263.

Paull TT, Lee J-H. 2005. The Mre11/Rad50/Nbs1 complex and its role as a DNA double-strand break sensor for ATM. Cell Cycle 4: 737-740.

Price BD, D'andrea AD. 2013. Chromatin remodeling at DNA double-strand breaks. Cell 152: 1344-1354.

Qi W, Wang R, Chen H, Wang X, Xiao T, Boldogh I, Ba X, Han L, Zeng X. 2015. BRG1 promotes the repair of DNA doublestrand breaks by facilitating the replacement of RPA with RAD51. J Cell Sci 128: 317-330.

Sartori AA, Lukas C, Coates J, Mistrik M, Fu S, Bartek J, Baer R, Lukas J, Jackson SP. 2007. Human CtIP promotes DNA end resection. Nature 450: 509-514.

Strobeck MW, Knudsen KE, Fribourg AF, DeCristofaro MF, Weissman BE, Imbalzano AN, Knudsen ES. 2000. BRG-1 is re- quired for RB-mediated cell cycle arrest. Proc Natl Acad Sci 97: 7748-7753.

Thangavel C, Boopathi E, Ciment S, Liu Y, O'Neill R, Sharma A, McMahon SB, Mellert H, Addya S, Ertel A, et al. 2014. The retinoblastoma tumor suppressor modulates DNA repair and radioresponsiveness. Clin Cancer Res 20: 5468-5482.

Tsai W-B, Chung YM, Takahashi Y, Xu Z, Hu MCT. 2008. Functional interaction between FOXO3a and ATM regulates DNA damage response. Nature 10: 460-467.

Velez-Cruz R, Johnson DG. 2012. E2F1 and p53 transcription factors as accessory factors for nucleotide excision repair. Int $J$ Mol Sci 13: 13554-13568.

Wang J, Gong Z, Chen J. 2011. MDC1 collaborates with TopBP1 in DNA replication checkpoint control. I Cell Biol 193: 267-273.

West SC. 2003. Molecular views of recombination proteins and their control. Nat Rev Mol Cell Biol 4: 435-445.

Wilson BG, Roberts CWM. 2011. SWI/SNF nucleosome remodellers and cancer. Nat Rev Cancer 11: 481-492.

Witkiewicz AK, Ertel A, McFalls J, Valsecchi ME, Schwartz G, Knudsen ES. 2012. RB-pathway disruption is associated with improved response to neoadjuvant chemotherapy in breast cancer. Clin Cancer Res 18: 5110-5122.

Xu Y, Sun Y, Jiang X, Ayrapetov MK, Moskwa P, Yang S, Weinstock DM, Price BD. 2010. The p400 ATPase regulates nucleosome stability and chromatin ubiquitination during DNA repair. J Cell Biol 191: 31-43.

Yu VP, Koehler M, Steinlein C, Schmid M, Hanakahi LA, van Gool AJ, West SC, Venkitaraman AR. 2000. Gross chromosomal rearrangements and genetic exchange between nonhomologous chromosomes following BRCA2 inactivation. Genes Dev 14: 1400-1406.

Zhang B, Wang E, Dai H, Shen J, Hsieh H-J, Lu X, Peng G. 2014. Phosphorylation of the BRCA1 C terminus (BRCT) repeat inhibitor of hTERT (BRIT1) protein coordinates TopBP1 protein recruitment and amplifies ataxia telangiectasia-mutated and Rad3-related (ATR) Signaling. J Biol Chem 289: 34284-34295.

Zou L. 2003. Sensing DNA damage through ATRIP recognition of RPA-ssDNA complexes. Science 300: 29-43. 


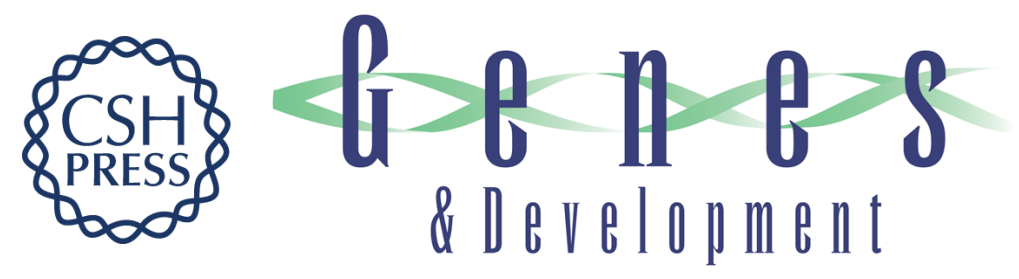

\section{RB localizes to DNA double-strand breaks and promotes DNA end resection and homologous recombination through the recruitment of BRG1}

Renier Vélez-Cruz, Swarnalatha Manickavinayaham, Anup K. Biswas, et al.

Genes Dev. 2016, 30:

Access the most recent version at doi:10.1101/gad.288282.116

Supplemental Material

References

Creative

Commons

License

Email Alerting

Service
http://genesdev.cshlp.org/content/suppl/2016/12/09/30.22.2500.DC1

This article cites 71 articles, 33 of which can be accessed free at: http://genesdev.cshlp.org/content/30/22/2500.full.html\#ref-list-1

This article is distributed exclusively by Cold Spring Harbor Laboratory Press for the first six months after the full-issue publication date (see http://genesdev.cshlp.org/site/misc/terms.xhtml). After six months, it is available under a Creative Commons License (Attribution-NonCommercial 4.0 International), as described at http://creativecommons.org/licenses/by-nc/4.0/.

Receive free email alerts when new articles cite this article - sign up in the box at the top right corner of the article or click here.

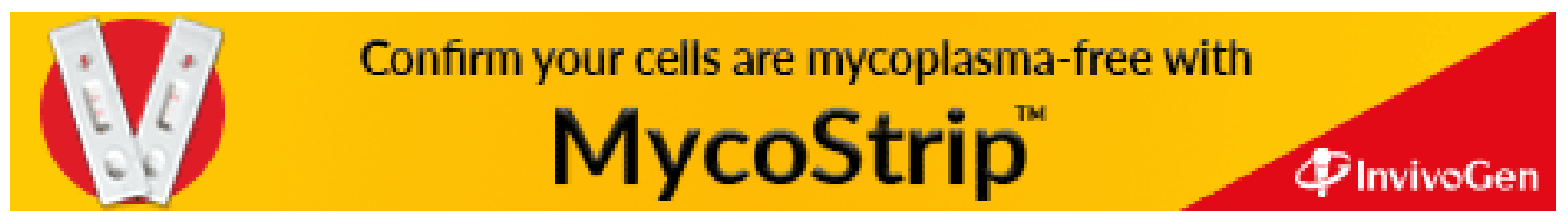

